\title{
Construction and Analysis on Evaluation System of Sports Resources
}

\author{
Shi Feng ${ }^{1, a}$ \\ ${ }^{1}$ The Security Department of Xingtai Medical College,Xingtai,Hebei,054000,China \\ asfylj1980@163.com
}

Keywords: sports resources; evaluation; construction; hierarchical analysis

\begin{abstract}
: this paper starts from perspective of resources and makes systematic research, discussion on connotation, classification and evaluation content of sports resources in city mass, it uses the past relevant research outcome to primarily establish evaluation and index system on sports resources for city mass, it also makes index selection through investigation on experts and scholars in aspects such as sports science and sociology etc, and constructs evaluation and index system on sports resources for city mass by integrating expert opinion, in addition, it adopts AHP to confirm weight of index system. From the final weight of index, we can see that material resources of mass sports is the most important in evaluation system on sports resources for city mass, the constructed evaluation system on sports resources for city mass is preliminary try, objective and feasible.
\end{abstract}

\section{Introduction}

With the rapid development in society and economy of China, gradual increase in disposable personal income and health consciousness, the mass population have drastic demand on sports demand, completely relying on government to plan and purchase sports resources can not meet development demand ${ }^{[1,2]}$ in sports career, they propose new requirements on intensive allocation and sustainable development. Sports resources the carrier and motivation for occurrence and existence of every sports situation, it is not only the base to develop contest sports activity, mass sports and social sports etc, but also the important support for development of sports industry, it can be also regarded as the important base and condition for regional economic development. The intensive allocation of sports resources is the necessary requirement on resources allocation and construction of two-oriented society, it is one of the guarantee measures ${ }^{[3,4]}$ to realize quick and stable development in sports career as well as the key point of making current sports resources produce social and economic benefit. However, because interest relation among object is so complicated, it will inevitably produce internal consumption in system in the reform process from planned economy to market economy, which will cause low performance in general target of sports resources. This paper uses the reconstructed comprehensive evaluation system on sports resources allocation in city school to get relevant data by site investigation and statistics on Zhengzhou, outline Lorenz curve of sports resources index in city school and get its Gini coefficient, it uses Gini coefficient to reflect evaluation and index system of sports resources for city mass, it also adopts AHP to confirm weight of index system. Material resources of mass sports are the most important in evaluation system on sports resources for city mass. The constructed evaluation system on sports resources for city mass is preliminary try, objective and feasible.

\section{Construction on evaluation system of sports resources}

The shortage in sports resources determines one society or area must use certain allocation method and model to distribute limited sports resources to field of society or area, So that it can realize optimal application of resources, which is to use the minimum, consumption to produce practicable sports goods and labor as well as obtain best profit. Scientific construction on evaluation system of sports resources is the base of realizing intensive allocation in sports resources. Construction on evaluation and index system of sports resources should persist in principles of systematic, dynamic, feasibility and operable except to observe the general discipline of statistics, 
only this can it establish a set of scientific, feasible and practicable evaluation and index system for sports resources. This paper possibly choose much more indexes and those with higher frequency by referring to full-text data base of Chinese journal and reading research literature on evaluation index construction of sports resources in China, it also makes selection on the repeated index or similar index, it also chooses detailed relevant index by combing with connotation and characteristic of Chinese sports resources as well as frame model of resources evaluation system. It is indicated by diagram 1, this paper finds and analyzes research(such as sport cash award of national mass, index system of progress award, evaluation system of social sports etc) on evaluation system of sports resources in China, it starts from the key content that can reflect evaluation fairness of sports resources for city mass, it mainly carries out experience choice for evaluation index of mass ports resources from aspects such as human resources, finance resources, material resources etc, which forms the evaluation and index system on sports resources for city mass contains 4 indexes of first class, 10 indexes of second class and 19 indexes of third class.

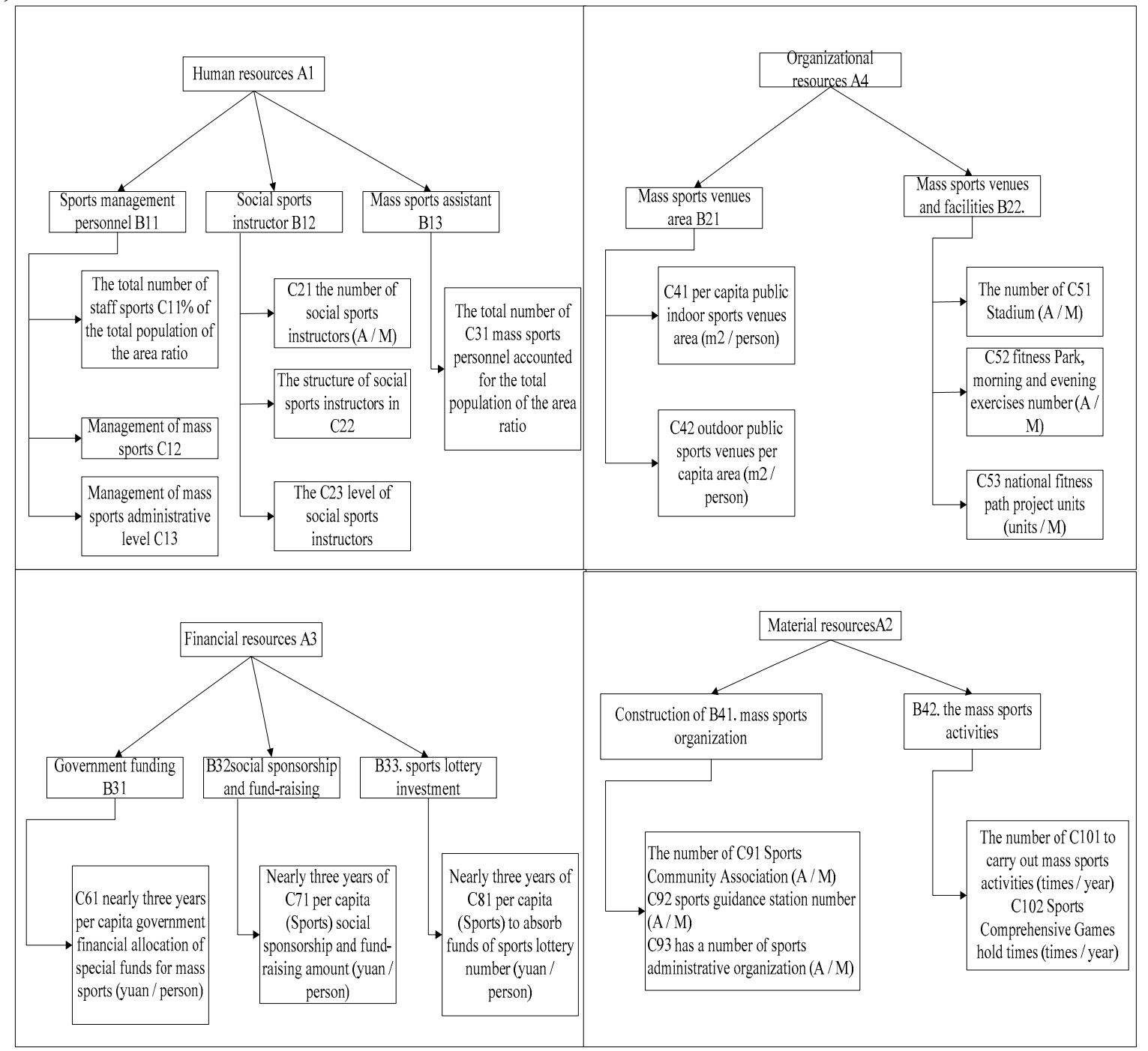

Diagram 1 Evaluation index system on sport resources for city mass

\section{Evaluation analysis on evaluation system of sports resources}

\section{Grade standard of evaluation index}

It adopts fuzzy analysis method to implement evaluation grade $\mathrm{D}=\{\mathrm{d} 1, \mathrm{~d} 2, \ldots, \mathrm{dn}\}$ and its subjection function. This paper divides evaluation grade of model into 4 grades, better, good, general, worse, and it also gives the corresponding threshold of each grade $\left\{\mathrm{d}_{1}, \mathrm{~d}_{2}, \ldots, \mathrm{d}_{\mathrm{n}}\right\}$, and then it makes comparative analysis on the above threshold according to subjection function, so that it gets 
evaluation grade of different indexes. This paper adopts methods of trapezoid distribution and semi trapezoid distribution to establish subjection function ${ }^{[1]}$, and gets distributed subjection function diagram indicated by diagram 2 , of which, $\mathrm{d}_{1}, \mathrm{~d} 2, \ldots, \mathrm{d} 5$ is the threshold under different grades, $\mathrm{c}_{1}$, $c_{2}, \ldots, c 5$ is respectively the midpoint placed in $\left[d_{1}, d 2\right],\left[d_{2}, d 3\right],\left[d_{3}, d 4\right],\left[d_{4}, d 5\right]$, so it gets threshold corresponds to grade according to the above methods.

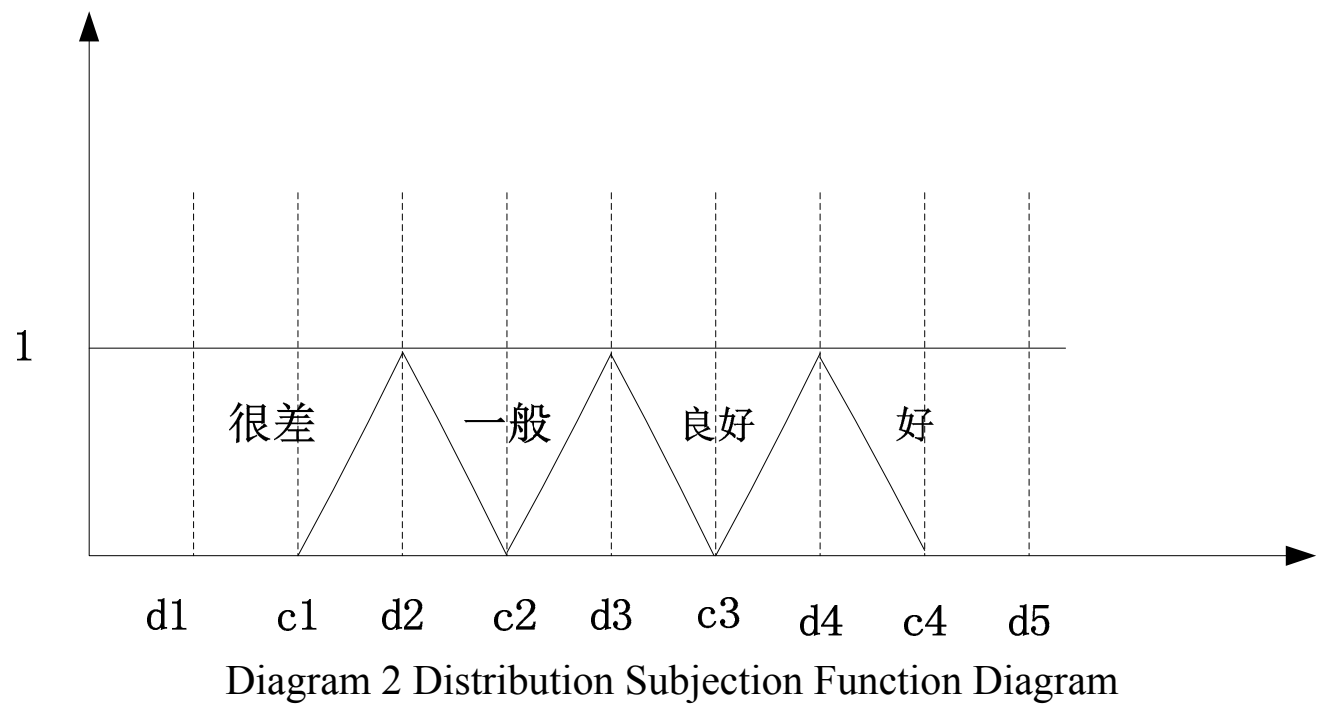

\section{Confirmation on evaluation index system weight of sports resources}

AHP discomposes elements related to determination into target, standard, plan etc, and it makes qualitative and quantitative analysis on determination method. It uses one complicated determination problem with multiple targets as one system to make analysis, discomposes this system into many targets or standards, so that discomposed into plenty of hierarchy with multi-index or standard, restriction. It calculates weight of single sequence and total sequence by fuzzy quantization method of qualitative index and uses it as systematic method for target with multiple indexes, multiple plan optimization. It establishes index weight matrix according to fuzzy hierarchy method, supposes there exists condition with $n$ index element, the symmetric matrix $A=\left\{A_{i j}\right\}_{n * n}$, of which, $A=\left\{A_{i j}\right\}_{n * n}$ indicates importance degree ratio of certain element $i$ on element $j$, its weight standard is indicated by table 1 .

Table 1 Weight standard of index

\begin{tabular}{|c|c|}
\hline importance degree of weight element & Grade of fuzziness \\
\hline $\begin{array}{l}\text { Element } \mathrm{i} \text { is important compared with } \\
\text { element } \mathrm{j}\end{array}$ & 1 \\
\hline $\begin{array}{l}\text { Element } \mathrm{i} \text { is slightly important than } \\
\text { element } \mathrm{j}\end{array}$ & 3 \\
\hline Element $\mathrm{i}$ is very important than element $\mathrm{j}$ & 5 \\
\hline Element $i$ is fairly important than element & 7 \\
\hline $\begin{array}{l}\text { Element } \mathrm{i} \text { is much more important than } \\
\text { element } \mathrm{j}\end{array}$ & $2,4,6$ \\
\hline
\end{tabular}

After comparison and analysis on weight ratio, it makes normalization processing on the above-mentioned matrix and gets the comparative weight value. This paper uses root method to make test on weight.

The formula (1) of calculating accordance index $\mathrm{C} 1$ is indicated as follows:

$$
C I=\frac{\lambda_{\text {max }}-n}{n-1}
$$


When $\mathrm{C} 1=0$, comparative matrix has complete accordance, the bigger of $\mathrm{C} 1$, the worse of accordance.

As for judgment matrix in stage from 1 to 9 , the average and random accordance index R1 value (table 2)

Table 2 R1 value corresponds to matrix order

\begin{tabular}{cccccccccc}
\hline $\begin{array}{c}\text { Matrix order } \\
(\mathrm{n})\end{array}$ & 1 & 2 & 3 & 4 & 5 & 6 & 7 & 8 & 9 \\
\hline RI & 0.00 & 0.00 & 0.58 & 0.90 & 1.12 & 1.24 & 1.32 & 1.41 & 1.45 \\
\hline
\end{tabular}

Accordance ratio CR (CR. Consistency Ratio) such as formula (2)

$$
C R=\frac{C I}{R I}
$$

When CR is less than 10, it indicates that accordance of judgment matrix is acceptable; otherwise it should make adjustment on judgment matrix again until it has satisfied accordance. It gets weight of index corresponds to index of the upper grade by single hierarchy single sequence method, it uses index weight of second grade and corresponding index weight of first grade to make integrated weight, it gets the weight coefficient of index of second grade corresponds to general target, it uses index weight of third grade and corresponding index weight of second grade to make integrated weight, it gets the weight coefficient of index of third grade corresponds to general target.

\section{Demonstration analysis on system evaluation of sports resources}

It totally distributes 20 pieces of expert questionnaire in AHP; the experts make matrix comparison on evaluation index of sports resources for mass city according to the above requirement, and it totally takes back 17 pieces and makes data analysis on these 17 pieces of expert questionnaire, as well as calculates index weight of each judgment matrix and makes accordance test, of which, there are 16 pieces of questionnaire with filled data is effective and it can pass accordance test, the accordance ratio CR of all the judgment matrix are all less than 0.1 , which indicates accordance in satisfaction. In the following, it uses questionnaire of one expert for example and indicates calculation result of each judgment matrix, it is equal to expert data analysis.

Table 3 Judgment matrix table on evaluation index system of first grade for mass sports resources

\begin{tabular}{|c|c|c|c|c|c|}
\hline & A1 & $\mathrm{A} 2$ & A3 & A4 & weight w \\
\hline A1 & $\begin{array}{l}\text { Human } \\
\text { resources }\end{array}$ & 1 & 1 & 3 & 0.3523 \\
\hline A2 & $\begin{array}{l}\text { material } \\
\text { resources }\end{array}$ & 1 & 1 & 3 & 0.3523 \\
\hline A3 & $\begin{array}{l}\text { finance } \\
\text { resources }\end{array}$ & $1 / 3$ & $1 / 3$ & 1 & 0.1822 \\
\hline A4 & $\begin{array}{l}\text { organization } \\
\text { resources }\end{array}$ & $1 / 5$ & $1 / 5$ & $1 / 5$ & 0.1122 \\
\hline
\end{tabular}

$\lambda \max =5.1958, C I=\lambda \max -\mathrm{n} / \mathrm{n}-1=5.1958-5 / 5-1=0.0489$, check table $\mathrm{RI}=1.12$, gets result that $\mathrm{CR}=\mathrm{CI}$

$/ \mathrm{RI}=0.0437\langle 0.10$, therefore, makes accordance test on this comparative matrix . 
Table 4 Judgment matrix table on evaluation index of second grade for human resources

\begin{tabular}{ccccc}
\hline A1-B & B11 & B12 & B13 & Weight w \\
\hline B11 Administrative staff of mass sports & 1 & 3 & 5 & 0.6483 \\
B12 social sports instructor & $1 / 3$ & 1 & 2 & 0.2297 \\
B13 人mass sports instructor & $1 / 5$ & $1 / 5$ & 1 & 0.1220 \\
\hline
\end{tabular}

Notes: $\lambda \max =3.0037, \quad \mathrm{CR}=0.0036\langle 0.10$, this accordance matrix passes accordance test.

Table 5 Judgment matrix on evaluation index of second grade for material resources

\begin{tabular}{llll}
\hline A2-B & B21 & B22 & Weight $\mathrm{w}$ \\
\hline B21 Place square of mass sports & 1 & $1 / 5$ & 0.1667 \\
B22 stadium facility of mass sports & 5 & 1 & 0.8333
\end{tabular}

Notes: $\lambda \max =2, \mathrm{CR}=0\langle 0.10$, this accordance matrix passes accordance test.

Table 6 Judgment matrix on evaluation index of second grade for finance resources

\begin{tabular}{ccccc}
\hline A3-B & B31 & B32 & B33 & Weight w \\
\hline B31 financial allocation of government & 1 & 5 & 5 & 0.7143 \\
B32 social support and fund & $1 / 5$ & 1 & 1 & 0.1429 \\
B33 Input in sports lottery & $1 / 5$ & 1 & 1 & 0.1429 \\
\hline
\end{tabular}

Notes: $\lambda \max =3, C R=0<0.10$, this accordance matrix passes accordance test.

Table 7 Judgment matrix on evaluation index of second grade for organization resources

\begin{tabular}{llll}
\hline A4-B & B41 & B42 & Weight \\
\hline $\begin{array}{l}\text { B41 organization construction for } \\
\text { mass sports }\end{array}$ & 1 & 5 & 0.8333 \\
$\begin{array}{l}\text { B42 Organization and activity } \\
\text { development conditions of mass } \\
\text { sports }\end{array}$ & $1 / 5$ & 1 & 0.1667 \\
& & &
\end{tabular}

Notes: $\lambda \max =2, \quad \mathrm{CR}=0\langle 0.10$, this comparative matrix passes accordance test.

According to the above judgment matrix, it calculates weight value on system index by 16 experts, because value cognition of experts has difference, the weight value of each other is different, but after passing accordance test, the credibility of questionnaire is tenable, it is regarded as weight with value. After getting weight value of 16 experts, it gets arithmetic average value of each index by calculation way of arithmetic average, it also makes further general sequencing and calculation by weight of each level, and finally it gets weight table on evaluation index system for mass sports. The research result and analysis indicate that among 5 indexes of first grade, material resources accounts for larger percentage in weight, it is 0.3974 , the weight of human resources is 0.1898 , weight of material resources is 0.2595 and weight of organization resources is 0.0834 , it can be seen that material resources is the most important to make evaluation on resources fairness for city mass.

\section{Summary}

Through classified research on sports resources, it makes classification on mass sports resources and confirms research content on mass sports resources according to classification and analysis on mass sports. Meanwhile, it introduces construction principle, construction method on evaluation index system for mass sports; it detailed constructs evaluation index system for mass sports. It calculates the relative importance degree of each index in the whole evaluation index system according to AHP, gets relative weight of each index in evaluation system of mass sports. From the final weight of index, we can see that material resources of mass sports are the most important in 
evaluation system for mass sports. The constructed evaluation system on sports resources for city mass is preliminary try, objective and feasible.

Table 8 Weight list on evaluation system of city mass sports resources

\begin{tabular}{|c|c|c|c|c|c|c|}
\hline \multirow{2}{*}{$\begin{array}{l}\text { Index of } \\
\text { first grade }\end{array}$} & \multicolumn{3}{|c|}{ Index of second grade } & \multicolumn{3}{|c|}{ Index of third grade } \\
\hline & Index & $\begin{array}{l}\text { Relative } \\
\text { weight } \\
\text { Index } \\
\text { weight }\end{array}$ & $\begin{array}{l}\text { Relative } \\
\text { to overall } \\
\text { Index } \\
\text { weight }\end{array}$ & Index & $\begin{array}{l}\text { Relative } \\
\text { to upper } \\
\text { grade } \\
\text { Index } \\
\text { weight }\end{array}$ & $\begin{array}{l}\text { Relative } \\
\text { to overall } \\
\text { Index } \\
\text { weight }\end{array}$ \\
\hline \multirow{7}{*}{ A1 } & \multirow{3}{*}{ B11 } & \multirow[t]{3}{*}{0.463} & \multirow[t]{3}{*}{0.087} & C11 & 0.4387 & 0.0385 \\
\hline & & & & $\mathrm{C} ! 2$ & 0.2602 & 0.0228 \\
\hline & & & & $\mathrm{C} 13$ & 0.3011 & 0.0264 \\
\hline & \multirow[t]{3}{*}{ B12 } & \multirow[t]{3}{*}{0.3853} & \multirow[t]{3}{*}{0.0732} & $\mathrm{C} 21$ & 0.5126 & 0.0375 \\
\hline & & & & $\mathrm{C} 22$ & 0.2371 & 0.0174 \\
\hline & & & & $\mathrm{C} 23$ & 0.2503 & 0.0183 \\
\hline & B13 & 0.1524 & 0.0289 & C31 & 1.000 & 0.0289 \\
\hline \multirow{5}{*}{$\mathrm{A} 2$} & \multirow{3}{*}{$\mathrm{C} 41$} & \multirow[t]{3}{*}{0.4667} & \multirow[t]{3}{*}{0.1855} & C91 & 0.4007 & 0.0743 \\
\hline & & & & $\mathrm{C} 92$ & 0.5993 & 0.1112 \\
\hline & & & & C93 & 0.3838 & 0.0813 \\
\hline & \multirow[t]{2}{*}{$\mathrm{C} 42$} & \multirow[t]{2}{*}{0.5333} & \multirow[t]{2}{*}{0.2119} & C101 & 0.3255 & 0.0690 \\
\hline & & & & $\mathrm{C} 102$ & 0.2907 & 0.0616 \\
\hline \multirow{3}{*}{ A3 } & B31 & 0.5575 & 0.1447 & C61 & 1.000 & 0.1447 \\
\hline & B32 & 0.1842 & 0.0478 & C71 & 1.000 & 0.0478 \\
\hline & B33 & 0.2583 & 0.0670 & C81 & 1.000 & 0.0670 \\
\hline \multirow{5}{*}{ A4 } & \multirow[t]{2}{*}{$\mathrm{B} 21$} & \multirow[t]{2}{*}{0.6287} & \multirow[t]{2}{*}{0.0524} & $\mathrm{C} 41$ & 0.4788 & 0.0251 \\
\hline & & & & $\mathrm{C} 42$ & 0.5212 & 0.0273 \\
\hline & \multirow{3}{*}{ B22 } & \multirow[t]{3}{*}{0.3713} & \multirow[t]{3}{*}{0.0310} & C51 & 0.6857 & 0.0213 \\
\hline & & & & C52 & 0.3143 & 0.0097 \\
\hline & & & & C53 & 0.5975 & 0.024 \\
\hline
\end{tabular}

\section{References}

[1] Dong Xinguang. Discussion on Unbalance and Reform Orientation of Public Sports Resources Allocation. Journal of Physical Education, 2007,Vol 12,p24.

[2] Wu Zhouli. Change and Relevant Problem Analysis on Allocation Manner of Sports Resources. Journal of Physical Education, 2007, Vol 7, p28-29..

[3] Liu Zhihong. Research on Construction and operability of Evaluation System in School Sports. Hebei Normal Univeristy,2007., p52-59..

[4] Research Topic Group on Rural Sports Evaluation Index System [EB/oL].Research on Index System in Rural Sports Evaluaton, 2005, Vol 24(4), p99-103.

[5] Xu Yanguo.Education Evaluation[M」.Higher Education Press,2007 .Vol3.

[6] ] Qi Xin, Zhang Bairui, Zhao Jimin. Construction and Measurement on World City Index System of Beijing. Research on City Development,2011,Vol 4 , p33-36.

[7] Song Wei. Research on Relations between Sports and economic Development of Chinese City. Journal of Beijing Sport University, 2004, Vol 6, p 736-738.

[8] Tang Lixu. Research on Enhancement and Channel Choice of Soft Power on City Sports [J]. Journal of Shandong Sports Institute,2010, Vol 4 p21-25.

[9] Zhou Xiqin. City Sports and City Image. The World of Sports Academic, 2010, Vol7, p108_-109. 
[10] Wang Ning, Zhao Nan. Discussion on Development Strategy of City Sports. Paper Special Journal of Postgraduate of Journal of Sports Institute of Shanxi Normal University, 2009, Vol $6, \mathrm{p}: 9-10$. 